\title{
Evaluation of some wheat genotypes to salt tolerance under antioxidant using physiological indices
}

\section{AA., Kandil ${ }^{1 *}$, AE., Sharief ${ }^{1}$ and}

Alkhamsa K. D. Botabaah ${ }^{2}$

${ }^{1}$ Department of Agronomy, Faculty of Agriculture, Mansoura University, Egypt.

${ }^{2}$ Faculty of Agriculture, Omar ElMoktar, El-Beda University, Libya

*Corresponding Author Email : sharief2005@yahoo.com
Salinity is the main limiting factor that adversely affecting germination, growth and yield of wheat in Egypt and Libya. A lab experiment was conducted in the seed lab, Agronomy Dept., Faculty of Agric., Mansoura University, Egypt during November and December 2016. The results clearly revealed that the high germination stress tolerance and root fresh stress indices obtained from Misr 1 cultivar. Meanwhile, the highest shoot length stress index from Misr 2 cultivar. The highest root length stress index, shoot fresh stress index, shoot dry stress index and root dry stress index recorded from Gemmiza 12 cultivar. The results indicated the highest stress tolerance index and shoot length stress index produced from which soaking, as pretreatment, in Ascorbic acid. These results have indicated that the highest stress tolerance index, root fresh stress index, shoot dry stress index and root dry stress index from the control treatments. Gradual increases in salinity concentrations from $40 \mathrm{mM}$ to $160 \mathrm{mM}$ significantly reduced germination stress tolerance, shoot and root length stress, shoot and root fresh stress, shoot and root dry stress indices. The highest percentages of germination stress tolerance, shoot length stress root length stress, shoot fresh stress, root fresh stress, shoot dry stress and root dry stress indices obtained from a salinity level of $40 \mathrm{mM}$. It could summarized that to enhance physiological indices; it could be optional to soak Gemmiza 12 or Misr 1 cultivars in Ascorbic acid at a concentration of $200 \mathrm{ppm}$ for $12 \mathrm{~h}$ under salinity stress.

Key words: Wheat cultivars, antioxidants, salinity levels, physiological measurements.

\section{INTRODUCTION}

The salinity of soil is a vital abiotic stress problem in Egypt and the World. Wheat genotypes differ in salt tolerance due to their genetic and types of salts in the soil. The highest salinity concentration inhabits percentage of seed germination and emergence of roots due to osmotic effect, which is harmful and prevents the plant in maintaining their appropriate nutritional necessities for their fit development. Genetic variations among genotypes of wheat provide a practical for screening to salt tolerant cultivars for improving breeding program. The highest salt tolerant genotypes are an inexpensive and actual approach to survive with stress of salinity (Arzani, 2008). Salinity reasons ion toxicity, osmotic stress, mineral deficiencies, which unfavorably affect physiological and biochemical processes limiting the crop productivity (Hamid et al., 2008).

The variation among the varieties and heritability were inferior under osmotic stress than under normal conditions. The studied germination characters, except, percentage of seed germination and seedling traits, excluding, shoot length showed more genetic variability (Dhanda et al., 2004). The difference between the varieties of the in physiological indices was happened during seed germination and early seedling establishments (Kausar et al., 2012). SARC-I (V5), Sehar-2006 (V8) and Shafaq-2006 (V9) genotypes had the higher tolerance indices and total 
chlorophyll contents (Naz et al., 2015). The bread wheat differed compared to einkorn wheat due to salt indices. The more salt tolerant of bread wheat genotypes compared with the einkorn wheat (Aslan et al., 2015). The wheat genotypes differ from the percentage of germination and seedling characters due to different salt levels, and recorded different salt tolerance indices that discriminates tolerant and susceptible varieties effectively (Oyiga et al., 2016). The genotypes of Kırmızı Yerli, Conkesme, and Türkmen were careful drought-resistant based on two out of the three physiological parameters indices. In addition, the genotypes of Yakar-99, Pehlivan, İzgi-2001, İkizce-96, Muzrak, and Gerek-79 considered drought-susceptible related to the physiological parameters indices (Ozturk et al., 2016). Sown Sids-13 cultivar appeared to the most tolerant cultivar shadowed by Misr-1, Misr-2, Gimmeza-9, Gimmeza-11, Sids-12, Sakha-93, Sakha-94, and Giza-186 cultivars and the last rank was Shadwell-1 cultivar with the maximum sensitivity (Mickky and Aldesuquy, 2017).

The agreements with high germination stress tolerance (GSTI), shoot length stress (PHSTI) indices and low relative saturation deficit (RSD) were more salt tolerant than the others, thus appear to promising for getting good productivity in salt-affected regions (Ashraf, 2006). Salt resistance is a characteristic quality of plants to endure the adversative properties in the root district (Odjegba and Chukwunwike, 2012). Osmotic adjustment, relative water content and specific leaf area can use as screening tools for drought resistant bread wheat genotypes in the greenhouse (Ahmed et al., 2014). Seawater significantly affected shoot growth of sorghum cultivars, but root development was dissimilar between genotypes even under normal water conditions. The more salt tolerant produced from C3 genotype, but $\mathrm{C} 4$ genotype was more salt sensitive (Bafeel, 2014). Sorgul genotype produces the highest root length. Dry root weight and recorded the most tolerant to salinity, because Altintoprak 98 genotype was the most tolerant as grand by the influence of salinity on length of shoots, weight of fresh seedling, germination rate and vigor index of seedling. The most sensitive to salinity-induced stress recorded by a Beyaziye variety (Yildirim et al., 2015). For salt tolerance, it could be use physiological indices to screen germplasm of wheat. The tolerant varieties can directly indorse for sown on soils affected by salinity or develop the high yielding salt tolerant wheat genotypes finished program of breeding (Zafar et al., 2015). Therefore, the goals of this investigate aimed to study the salt tolerance of wheat cultivars using some physiological parameters, i.e. germination stress index, shoot and root length stress index, fresh and dry stress index for both shoot and root.

\section{MATERIALS AND METHODS}

\section{Treatments and Experimental Design}

In seed lab of the Agronomy Department, Faculty of Agriculture, Mansoura University, Egypt an experiment organized during November and December 2016, to study the response of antioxidants seed prim of some bread wheat cultivars to germinate under salinity stress. In a factorial experiment in Randomized Complete Block Design in four replication used. The four bread wheat varieties, Sakha 94, Misr-1, Misr-2 and Gemmiza-12 includes the first factor. The three types of antioxidants, Salicylic acid, Ascorbic acid and Humic acid includes the second factor. The three concentrations of studied antioxidants 0,100 and $200 \mathrm{ppm}$ include the third factor. The fourth factor includes the five salinity levels $0,40,80,120$ and $160 \mathrm{mM}$. Selected cultivars obtained from wheat section, Field Crop Institute, ARC. Each cultivar was prim in the three antioxidants at above concentrations of 12 hours. Each cultivar irrigated with sodium chloride solution as above concentrations under the chamber condition at $25 \pm 1^{\circ} \mathrm{c}$ with darkness. Thereafter, seeds moistened with distilled water under control treatments. The prim seeds in antioxidants and non-primed seed of study cultivars was sowing in Petri dishes used fifty seeds per each treatment for each cultivar were allowed to germinate on Petri dishes moistened with a water solution at five different $\mathrm{NaCl}$ concentrations except the control. The experiment comprised of 720 Petri dishes arranged in a factorial experiment in Randomized Complete Block Design (RCBD) on four replication the roll paper placed in a growth chamber for 12 days at $25- \pm 1{ }^{\circ} \mathrm{C}$ for germination (according to ISTA, 2016).

\section{Studied Characters}

Bread wheat seed of study cultivars subjected for determination of physiological indices. The promptness index (PI) was projected according to (Ashraf et al. (2006) formula as follows:

$$
\text { Promptness index }(\mathrm{PI})=n d 1(1.00)+n d 2(0.75)+n d 3(0.50)+n d 4(0.25)
$$

Where $\mathrm{nd}_{1}, \mathrm{nd}_{2}, \mathrm{nd}_{3}$ and $\mathrm{nd}_{4}=$ Number of seeds germinated on the $1^{\text {st }}, 2^{\text {nd }}, 3^{\text {rd }}$ and $4^{\text {th }}$ day, respectively.

The calculation of germination stress tolerance index percentage (GSI) as follows:

1-Germination stress tolerance index (GSTI) = It calculated according the following formula:

$$
\text { GSTI }=\frac{\text { PI of stress seeds }}{\text { PI of control seeds }} \times 100
$$

After 14 days of the experiment, shoot and root lengths and fresh weights were calculated. The seedling, dried at $70^{\circ} \mathrm{C}$ for two days and their dry weight recorded. The physiological parameters were calculated as follows:

2- Shoot length stress index (PHSI): It calculated according the following formula:

PHSI $=\frac{\underset{i}{\text { Shoot } 1 \text { ength of stressed seeds }}}{\text { Shoot length of the control }} \times 100$.


3- Root length stress index (RLSI) = It calculated according the following formula:

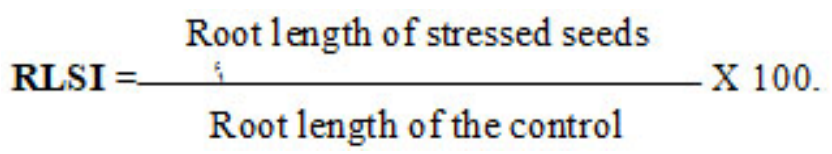

4- Shoot fresh stress index (SFSI) = It calculated according the following formula:

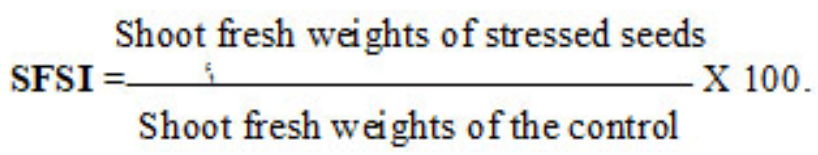

5- Root fresh stress index (RFSI) = It calculated according the following formula:

\section{Root fresh weights of stressed seeds RFSI $=\longrightarrow$ X 100 . \\ Root fresh weights of the control}

6- Shoot dry stress index (SDSI) = It calculated according the following formula:

\section{SDSI $=\frac{\text { Shoot dry weights of stressed seeds }}{i} \times 100$. \\ Shoot dry weights of the control}

7- Root dry stress index (RDSI) = It calculated according the following formula:

$$
\text { RDSI }=\frac{\text { Root dry weights of stressed seeds }}{\text { Root dry weights of the control }} \times 100 .
$$

\section{Experimental analysis}

The collected data was analysis, statistically by the technique of analysis of variance using the MSTAT-C statistical package programmed as described by a procedure of Gomez and Gomez (1991). Lest significant differences test (LSD) for 5 and $1 \%$ level of probability take place for comparing between treatment means, according to Snedecor and Cochran (1980).

\section{RESULTS AND DISCUSSION}

\section{Cultivar Performance}

Averages of germination stress tolerance, shoot and root length stress, shoot and root fresh stress, shoot and dry stress and root dry stress indices as affected by antioxidants types, antioxidants levels, and salinity concentrations of some wheat cultivars are shown in Tables (1 and 2). The results clearly revealed that germination stress tolerance, shoot and root length stress, shoot and root fresh stress, shoot and dry stress and root dry stress indices were significantly influenced by studying bread wheat cultivars. The highest germination stress tolerance index (57.15) and root fresh stress index (67.28) were obtained from sowing Misr 1 cultivar. Meanwhile, the highest shoot length stress index (63.4) from sown Misr 2 cultivar. The highest root length stress index (46.88), soot fresh stress index (60.03, shoot dry stress index (60.8) and root dry stress index (67.33) were recorded from sown Gemmiza 12 cultivar. However, the lowest values of germination stress tolerance, shoot and root length stress, shoot fresh stress and root dry stress indices were produced from sown Sakha 94 cultivar and the lowest values of root fresh stress index and shoot dry stress index were obtained from sown Misr 2 cultivar. The difference between the varieties of the in physiological indices was happened during seed germination and early seedling establishments (Kausar et al., 2012). SARC-I (V5), Sehar2006 (V8) and Shafaq-2006 (V9) genotypes had the higher tolerance indices and total chlorophyll contents (Naz et al., 2015). The genotypes of Kırmızı Yerli, Conkesme, and Türkmen were careful drought-resistant based on two out of the three physiological parameters indices. In addition, the genotypes of Yakar-99, Pehlivan, İzgi-2001, İkizce-96, Mızrak, and Gerek-79 considered drought-susceptible related to the physiological parameters indices (Ozturk et al., 2016). Sown Sids-13 cultivar appeared to the most tolerant cultivar shadowed by Misr-1, Misr-2, Gimmeza-9, Gimmeza-11, Sids-12, Sakha-93, Sakha-94, and Giza-186 cultivars and the last rank was Shadwell-1 cultivar with the maximum sensitivity (Mickky and Aldesuquy, 2017)

\section{Antioxidants Types Effects}

The results presented in Tables ( 1 and 2) clearly revealed that germination stress tolerance and shoot length stress indices significantly influenced by antioxidant types, except, root length stress, shoot and root fresh stress, shoot and root dry stress indices were insignificantly effected. The results indicated the highest germination stress tolerance index (51.76) and shoot length stress index (61.88) were produced from soaking as pretreatment in Ascorbic acid. However, the lowest germination stress tolerance index obtained from soaking in Salicylic acid and the lowest shoot length stress index from soaking in Humic acid. The agreements with high germination stress tolerance (GSTI), shoot length stress (PHSTI) indices and low relative saturation deficit (RSD) were more salt tolerant than the others, thus appear to promising for getting good productivity in salt-affected regions (Ashraf, 2006). For salt tolerance, it could be use physiological indices to screen germplasm of wheat. The tolerant varieties can directly indorse for sown on soils affected by salinity or develop the high yielding salt tolerant wheat genotypes finished 
Table 1. Averages of germination stress tolerance, shoot and root length stress and shoot fresh indices as affected by antioxidants types, levels, and salinity concentrations of some wheat cultivars as well as their interactions

\begin{tabular}{|c|c|c|c|c|}
\hline $\begin{array}{l}\text { Characters } \\
\text { Treatments }\end{array}$ & Stress tolerance index & $\begin{array}{c}\begin{array}{c}\text { Shoot length stress } \\
\text { index }\end{array} \\
\end{array}$ & $\begin{array}{c}\text { Root length stress } \\
\text { index }\end{array}$ & $\begin{array}{c}\text { Shoot fresh stress } \\
\text { index }\end{array}$ \\
\hline \multicolumn{5}{|l|}{ A. Cultivars: } \\
\hline Sakha 94 & 35.27 & 55.12 & 28.15 & 52.10 \\
\hline Misr 1 & 57.15 & 62.57 & 37.28 & 58.14 \\
\hline Misr 2 & 48.38 & 64.30 & 40.76 & 59.74 \\
\hline Gemmiza 12 & 56.74 & 63.11 & 46.88 & 60.03 \\
\hline F. test & * & * & * & * \\
\hline LSD at 0.05 & 1.03 & 0.74 & 0.78 & 1.32 \\
\hline \multicolumn{5}{|c|}{ B. Antioxidants types: } \\
\hline Humic acid & 50.78 & 60.96 & 38.26 & 57.37 \\
\hline Salicylic acid & 45.62 & 60.98 & 38.09 & 57.67 \\
\hline Ascorbic acid & 51.76 & 61.88 & 38.47 & 57.48 \\
\hline F. test & $*$ & $*$ & NS & NS \\
\hline LSD at 0.05 & 0.89 & 0.64 & - & - \\
\hline \multicolumn{5}{|c|}{ C. Antioxidants levels: } \\
\hline Control & 49.98 & 61.01 & 38.24 & 57.95 \\
\hline $100 \mathrm{ppm}$ & 49.77 & 61.25 & 38.67 & 57.43 \\
\hline $200 \mathrm{ppm}$ & 48.40 & 61.56 & 37.90 & 57.13 \\
\hline F. test & * & NS & NS & NS \\
\hline LSD at 0.05 & 0.89 & - & - & - \\
\hline \multicolumn{5}{|c|}{ D. Salinity concentrations: } \\
\hline $0 \mathrm{mM}$ & 0.00 & 0.00 & 0.00 & 0.00 \\
\hline $40 \mathrm{mM}$ & 93.02 & 95.05 & 79.47 & 90.91 \\
\hline $80 \mathrm{mM}$ & 75.82 & 85.37 & 52.78 & 79.24 \\
\hline $120 \mathrm{mM}$ & 51.14 & 71.65 & 36.17 & 65.97 \\
\hline $160 \mathrm{mM}$ & 26.96 & 54.29 & 22.94 & 51.39 \\
\hline F. test & $*$ & $*$ & $*$ & $*$ \\
\hline LSD at 0.05 & 1.16 & 0.82 & 0.87 & 1.47 \\
\hline \multicolumn{5}{|l|}{ C. Interactions F. test: } \\
\hline $\mathrm{B} \times \mathrm{A}$ & $*$ & * & * & N.S. \\
\hline $\mathrm{C} \times \mathrm{A}$ & N.S. & N.S. & * & N.S. \\
\hline$D \times A$ & $*$ & N.S. & $*$ & * \\
\hline $\mathrm{C} \times \mathrm{B}$ & * & $*$ & N.S. & N.S. \\
\hline$D \times B$ & * & N.S. & N.S. & N.S. \\
\hline $\mathrm{D} \times \mathrm{C}$ & * & $*$ & N.S. & $*$ \\
\hline
\end{tabular}

program of breeding (Zafar et al., 2015).

\section{Antioxidants Concentrations Effects:}

The results presented in Tables (1 and 2) clearly revealed that germination stress tolerance, root fresh stress, shoot and root dry stress indices were significantly influenced by antioxidant concentrations, except, shoot and root length stress and shoot fresh stress indices were insignificantly effected. The results indicated that the highest germination stress tolerance index (49.98), root fresh stress index (63.53), shoot dry stress index (58.51) and root dry stress index (63.84) from the control treatments and the lowest values from increasing antioxidant concentration until 200 ppm. Kandil et al. (2017) reported that soaking in humic acid recorded the highest salinity tolerance index. Seed soaking in humic acid exceeded tolerance index by $40.8 \%$ compared without soaking in humic acid.

\section{Salinity Stress Effects}

Regarding to results of means of germination stress tolerance, shoot and root length stress, shoot and root fresh stress, shoot and root dry stress indices, the results in Tables ( 1 and 2) clearly showed that these characters were significantly affected. The results revealed that cumulative salinity levels from $40 \mathrm{mM}$ to $160 \mathrm{mM}$ significantly reduced germination stress tolerance, shoot and root length stress, shoot and root fresh stress, shoot and root dry stress indices. The highest percentages of germination stress tolerance index (93.02), shoot length stress index (95.05) root length stress index (79.47), shoot fresh stress index (90.91), root fresh stress index (90.94), shoot dry stress index (91.09) and root dry stress index (90.44) were obtained from a salinity level of $40 \mathrm{mM}$. Whereas, the lowest percentages of above mentioned characters on salinity level of $160 \mathrm{mM}$. The agreements with high 
Table 2. Averages of root fresh stress, shoot dry stress and root dry stress indices as affected by antioxidants types, levels, and salinity concentrations of some wheat cultivars as well as their interactions.

\begin{tabular}{|c|c|c|c|}
\hline $\begin{array}{l}\text { Characters } \\
\text { Treatments }\end{array}$ & Root fresh stress index & Shoot dry stress index & Root dry stress index \\
\hline \multicolumn{4}{|l|}{ A. Cultivars: } \\
\hline Sakha 94 & 64.10 & 56.30 & 55.50 \\
\hline Misr 1 & 67.28 & 53.91 & 63.56 \\
\hline Misr 2 & 59.11 & 53.57 & 66.28 \\
\hline Gemmiza 12 & 60.47 & 60.86 & 67.33 \\
\hline F. test & ${ }^{*}$ & * & ${ }^{*}$ \\
\hline LSD at 0.05 & 1.57 & 2.27 & 1.38 \\
\hline \multicolumn{4}{|l|}{ B. Antioxidants types: } \\
\hline Humic acid & 62.48 & 56.03 & 63.21 \\
\hline Salicylic acid & 62.83 & 56.35 & 63.16 \\
\hline Ascorbic acid & 62.90 & 56.09 & 63.14 \\
\hline F. test & NS & NS & NS \\
\hline \multirow{2}{*}{\multicolumn{4}{|c|}{ C. Antioxidants levels: }} \\
\hline & & & \\
\hline Control & 63.53 & 58.51 & 63.84 \\
\hline $100 \mathrm{ppm}$ & 62.91 & 56.93 & 63.42 \\
\hline $200 \mathrm{ppm}$ & 61.78 & 53.04 & 62.25 \\
\hline F. test & * & $*$ & $*$ \\
\hline LSD at 0.05 & 1.36 & 1.97 & 1.19 \\
\hline \multicolumn{4}{|l|}{ D. Salinity concentrations: } \\
\hline $0 \mathrm{mM}$ & 0.00 & 0.00 & 0.00 \\
\hline $40 \mathrm{mM}$ & 90.94 & 91.09 & 90.44 \\
\hline $80 \mathrm{mM}$ & 82.66 & 78.88 & 82.64 \\
\hline $120 \mathrm{mM}$ & 74.20 & 64.87 & 75.23 \\
\hline $160 \mathrm{mM}$ & 65.89 & 46.66 & 67.54 \\
\hline F. test & * & * & * \\
\hline LSD at 0.05 & 1.75 & 2.54 & 1.54 \\
\hline \multicolumn{4}{|l|}{ C. Interactions F. test: } \\
\hline $\mathrm{B} \times \mathrm{A}$ & N.S. & N.S. & N.S. \\
\hline $\mathrm{C} \times \mathrm{A}$ & N.S. & N.S. & N.S. \\
\hline$D \times A$ & * & $*$ & $*$ \\
\hline $\mathrm{C} \times \mathrm{B}$ & N.S. & N.S. & N.S. \\
\hline $\mathrm{D} \times \mathrm{B}$ & N.S. & N.S. & N.S. \\
\hline $\mathrm{D} \times \mathrm{C}$ & $*$ & N.S. & N.S. \\
\hline
\end{tabular}

germination stress tolerance (GSTI), shoot length stress (PHSTI) indices and low relative saturation deficit (RSD) were more salt tolerant than the others, thus appear to promising for getting good productivity in salt-affected regions (Ashraf, 2006). Accumulative salinity up to $15 \mathrm{dSm}^{-}$ ${ }^{1}$ significantly abridged stress tolerance index by and 57.4 $\%$ compared with the control treatment (Kandil et al., 2017). Salt resistance is a characteristic quality of plants to endure the adversative properties in the root zone (Odjegba and Chukwunwike, 2012). Osmotic adjustment, relative water content and specific leaf area can use as screening tools for drought resistant bread wheat genotypes in the greenhouse (Ahmed et al., 2014). Seawater significantly affected shoot growth of sorghum cultivars, but root development was dissimilar between genotypes even under normal water conditions. The more salt tolerant produced from C3 genotype, but C4 genotype was more salt sensitive (Bafeel, 2014). Similar conclusions were recorded with those reported by Ma et al. (2014); Yildirim et al. (2015); (Zafar et al. (2015) and Ozturk et al. (2016).

\section{Interaction Effects}

\section{Interaction between cultivars and antioxidants types effect}

Concerning to the interaction between cultivars and antioxidants types effects on the stress tolerance index, shoot and root length stress index, shoot dry stress index and root dry stress index significantly influenced by this interaction. The results clearly graphically illustrated in Figure. 1, 2, 3, 4 and 5 indicated that soaking seed of Gemmiza 12 cultivar in Ascorbic acid significantly produced the highest percentages of stress tolerance index (60.41), shoot length stress index (64.37), root length stress index (46.86), shoot dry stress index (62.93) and root dry stress 


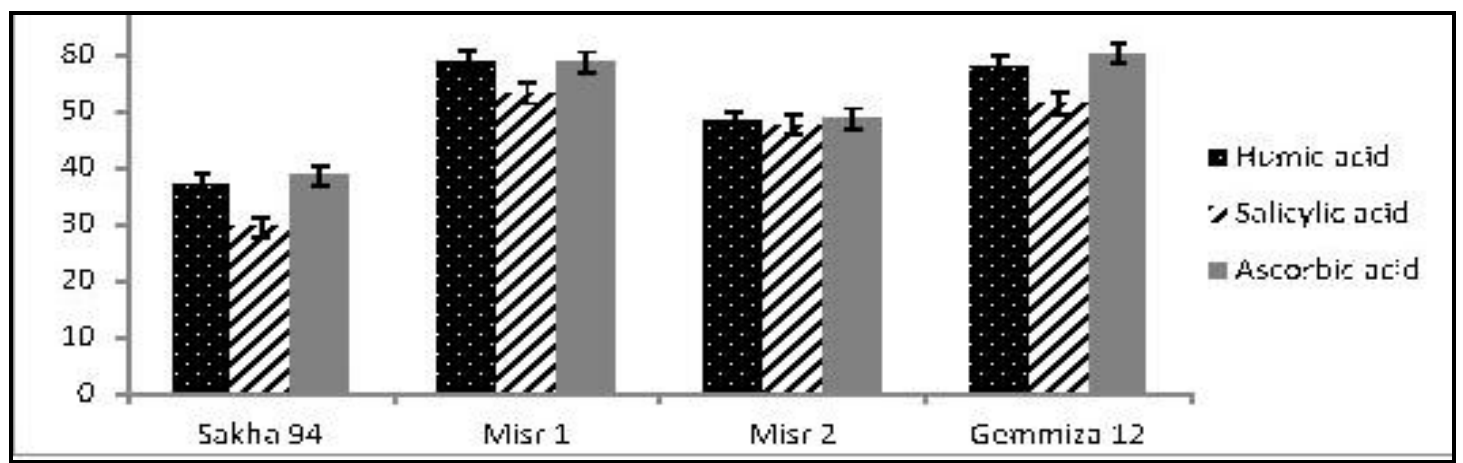

Figure 1: Average of germination stress tolerance index (GSTI) as influenced by the interface between wheat cultivars and antioxidants types.

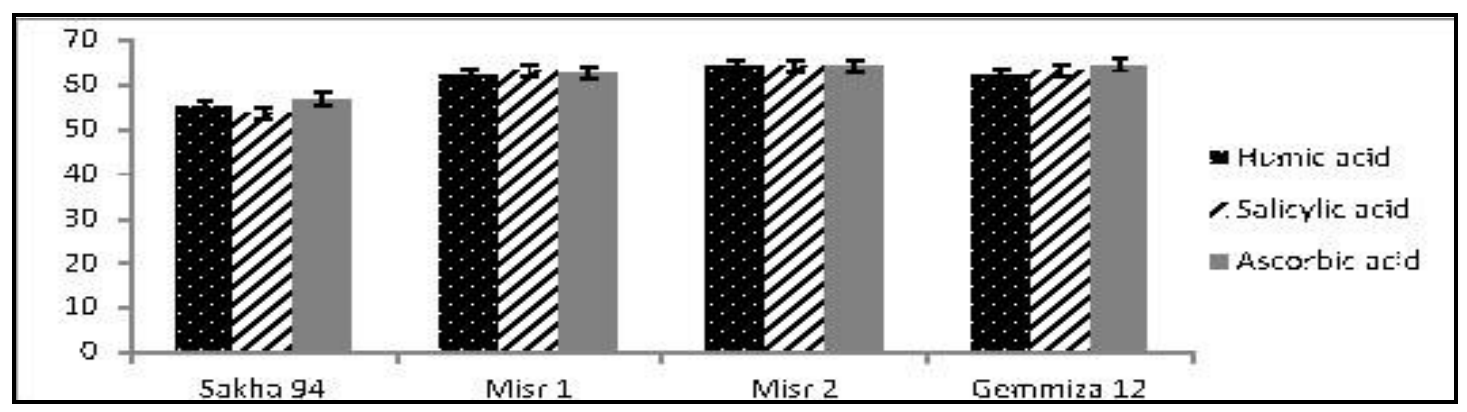

Figure 2: Average of shoot length stress index (SLSI) as exaggerated by the interface between wheat cultivars and antioxidants types.

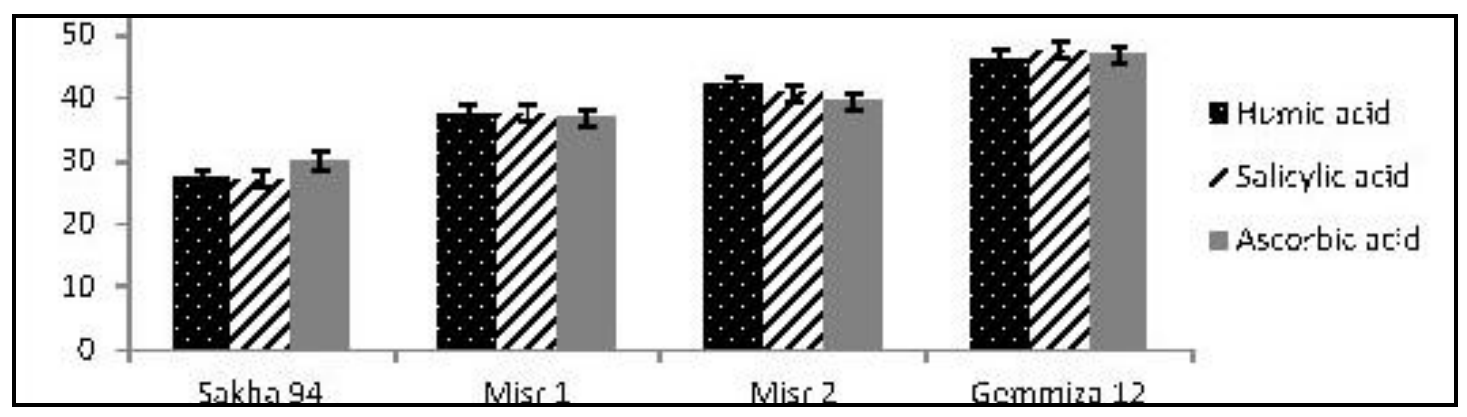

Figure 3: Means of root length stress index (RLSI) as influenced by the interface Average wheat cultivars and antioxidants types.

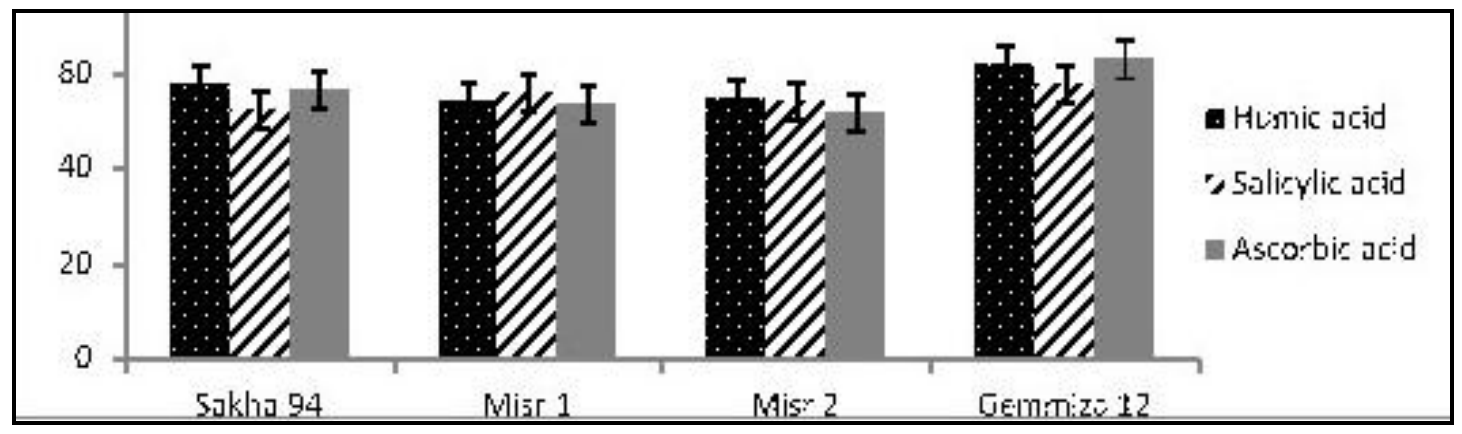

Figure 4: Average of shoot dry stress index (SDSI) as exaggerated by the interface between wheat cultivars and antioxidants types. 


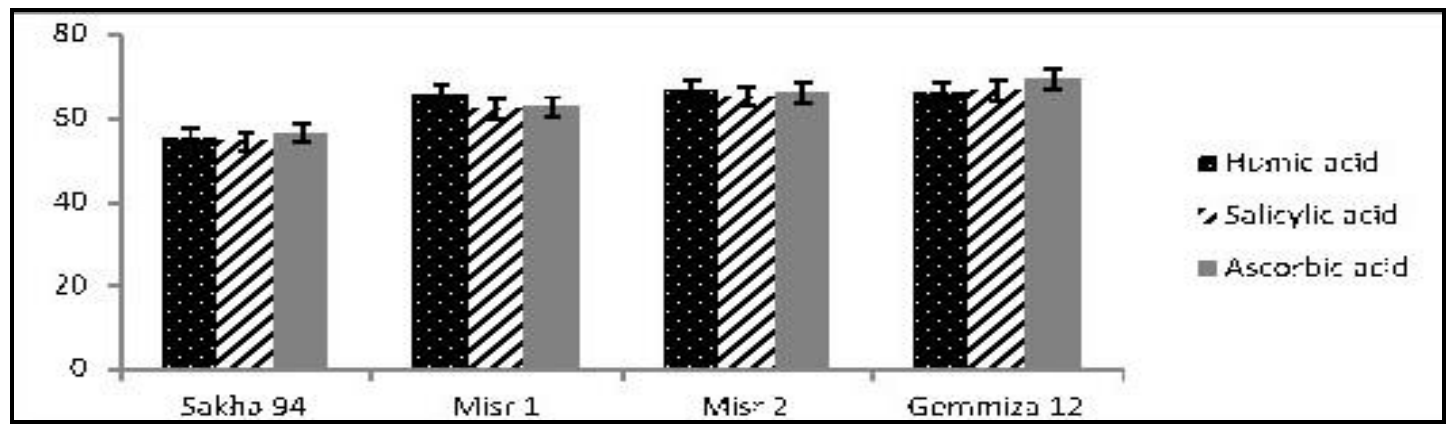

Figure 5: Average of root dry stress index (RDSI) as influenced by the interface between wheat cultivars and antioxidants types.

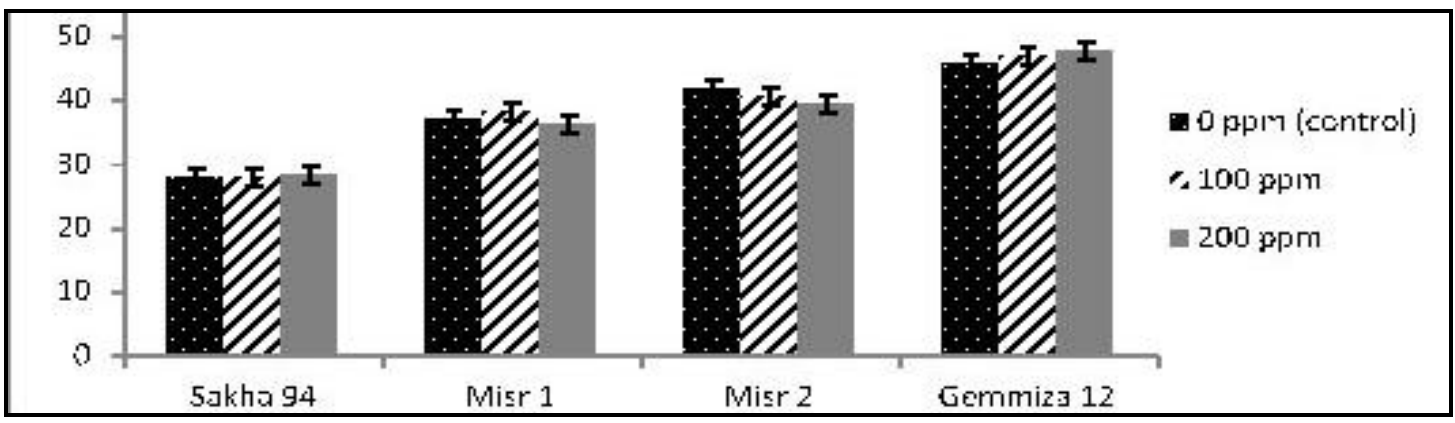

Figure 6: Average of root length stress index (RLSI) as influenced by the interface between wheat cultivars and antioxidants levels.

index (69.62). Nevertheless soaking seed of Sakha 94 cultivar in Salicylic acid significantly produced the highest percentages of stress tolerance index (29.74), shoot length stress index (53.61), root length stress index (27.09), shoot dry stress index (52.20) and root dry stress index (54.52). The highest values of stress tolerance index (90.05) were recorded from sown Giza 15 cultivar with soaking in humic acid (Kandil et al., 2017).

\section{Interaction between cultivars and antioxidant concentration effect}

With reference to the interaction between cultivars and antioxidant concentration effects on the root length stress index was significantly influenced by this interaction. The results clearly graphically demonstrated in Figure 6 revealed that soaking seed of Gemmiza 12 cultivar in antioxidants at a concentration of $20 \mathrm{ppm}$ significantly produced the highest percentages of root length stress index (47.88), however the lowest percentages (27.9) was obtained from without soaking in antioxidants of Sakha 94 cultivar.

\section{Interaction between cultivars and salinity levels effect}

Concerning to the interaction between cultivars and salinity concentration effects on the germination stress tolerance, root length stress, shoot and root fresh stress, shoot and root dry stress indices were significantly influenced by this interaction. The results clearly graphically exemplified in Figure 7, 8, 9, 10, 11 and 12 exposed that germination stress tolerance, root length stress, shoot and root fresh stress, shoot and root dry stress indices were reduced with salinity levels were increased in all studied cultivars. It could recorded that the highest percentages of germination stress tolerance index (96.09), root length stress index (89.65), shoot fresh stress index (92.22), root fresh stress index (94.39), shoot dry stress index (91.09) and root dry stress index (92.0) were produced from sowing Misr 1 cultivar under the salinity level of $40 \mathrm{mM}$. Whereas, the lowest percentages from above characters were obtained from sown Sakha 94 cultivar under highest salinity level of $160 \mathrm{mM}$. For salt tolerance, it could be use physiological indices to screen germplasm of wheat. The tolerant varieties can directly indorse for sown on soils affected by salinity or can used to develop high yielding salt tolerant wheat cultivars through breeding program (Zafar et al., 2015). The highest stress tolerance index (100 80.13 and $79.5 \%$ ) was produced from sown Mecca hybrid at without salinity and at salinity level of $3 \mathrm{dSm}^{-1}$ without significant difference as well as between Giza 15 cultivar at salinity level of $6 \mathrm{dSm}^{-1}$, respectively (Kandil et al., 2017). Similarly, Bafeel (2014); Ma et al. (2014) and Yildirim et al. (2015) to the same conclusions. 


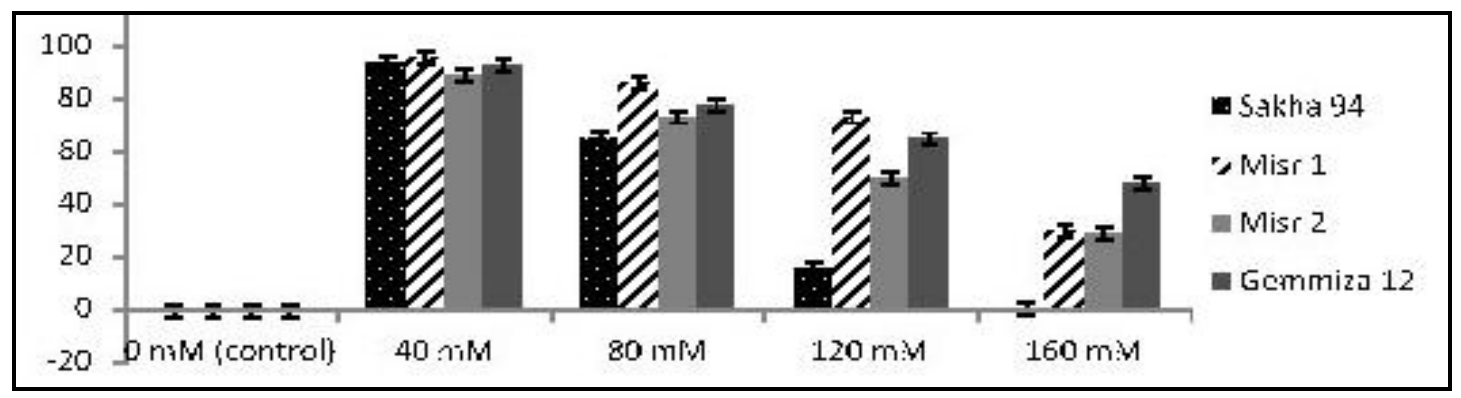

Figure 7: Averages of germination stress tolerance index (GSTI) as influenced by the interaction between wheat cultivars and salinity levels.

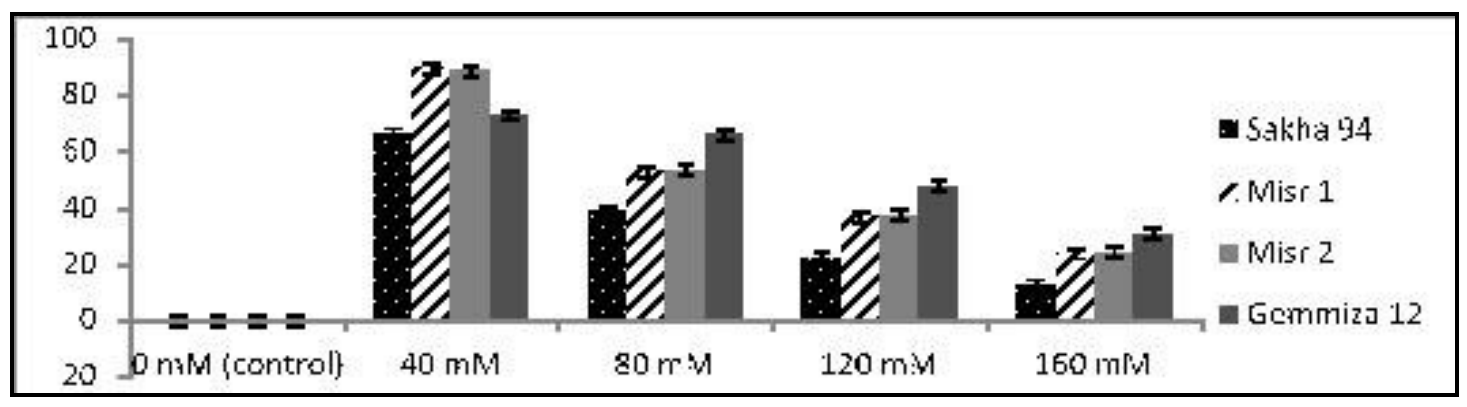

Figure 8: Averages root length stress index (RLSI) as influenced by the interaction between wheat cultivars and salinity levels.

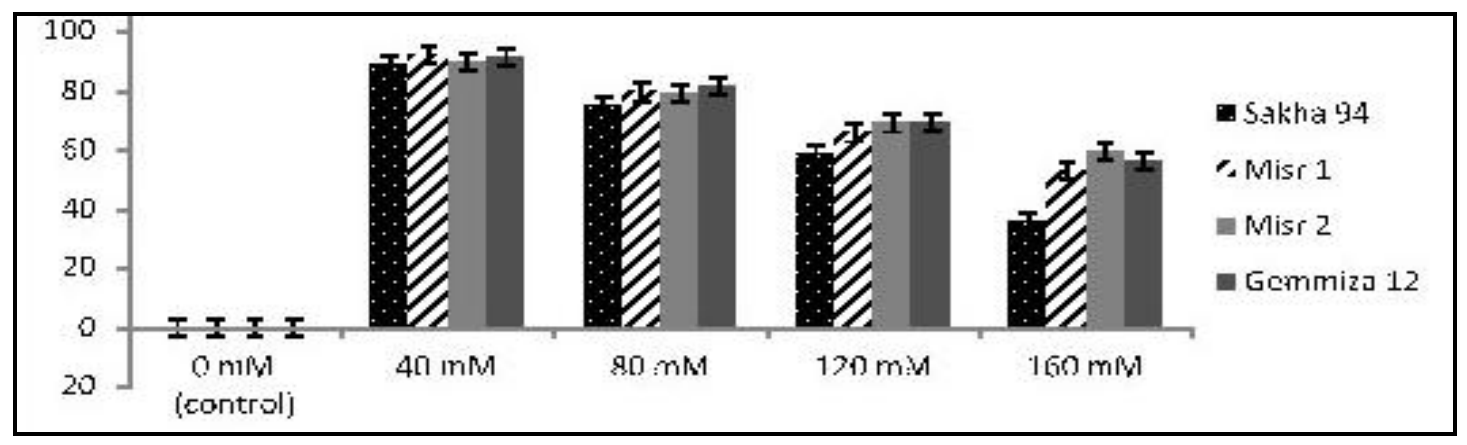

Figure 9: Averages of shoot fresh stress index (SFSI) as influenced by the interaction between wheat cultivars and salinity levels.

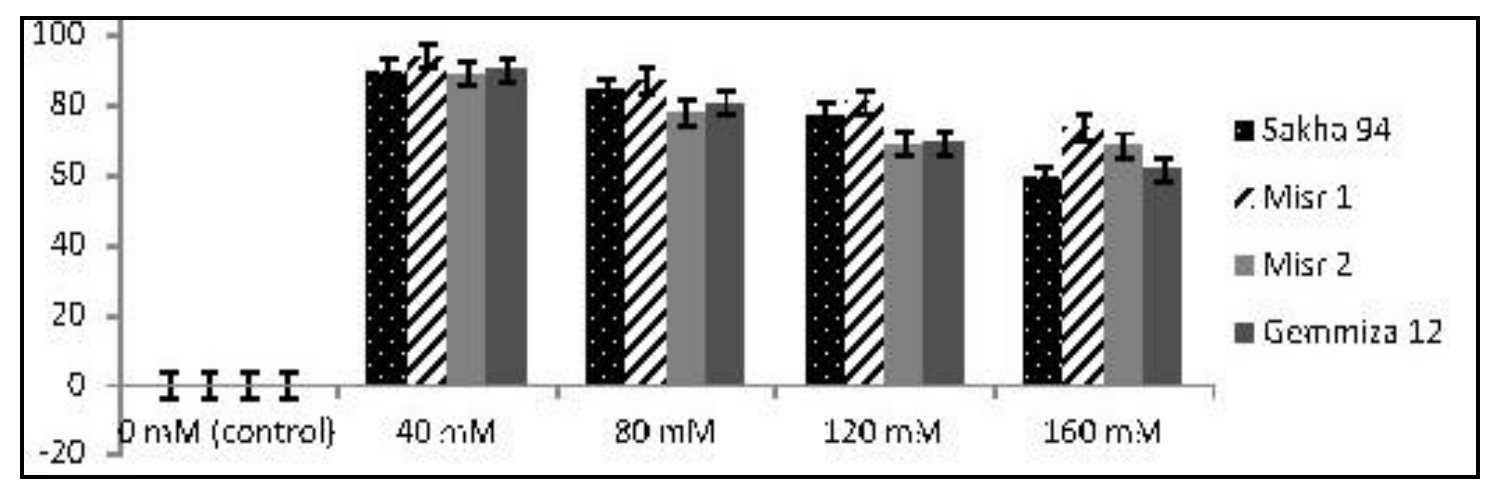

Figure 10: Averages of root fresh stress index (RFSI) as influenced by the interaction between wheat cultivars and salinity levels. 


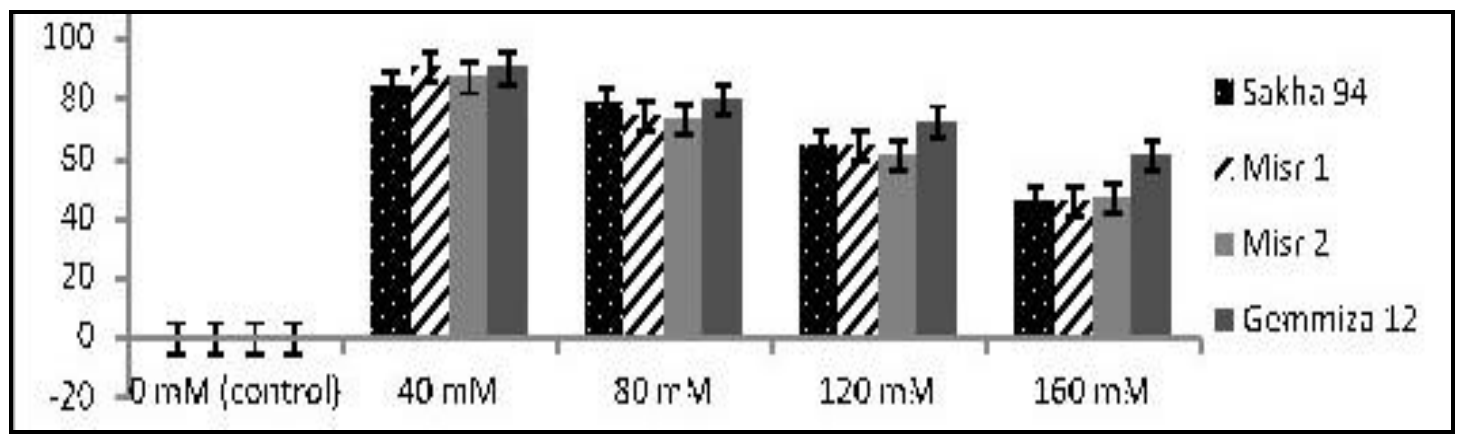

Figure 11: Averages of shoot dry stress index (SDSI) as influenced by the interaction between wheat cultivars and salinity levels.

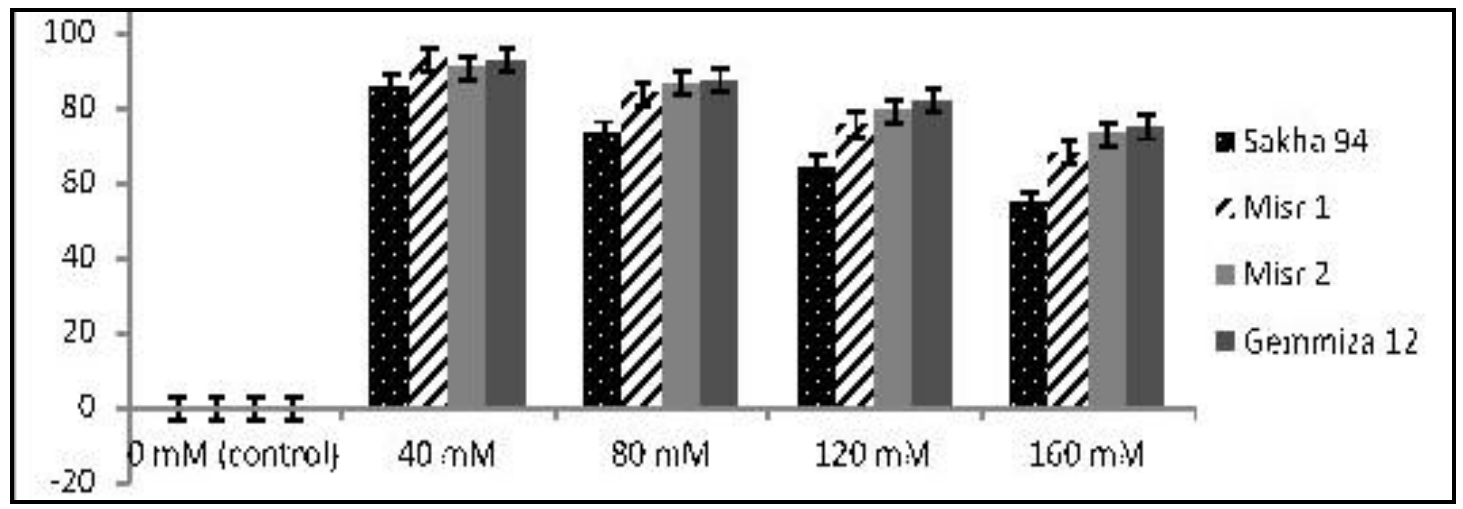

Figure 12: Averages of root dry stress index (RDSI) as influenced by the interaction between wheat cultivars and salinity levels.

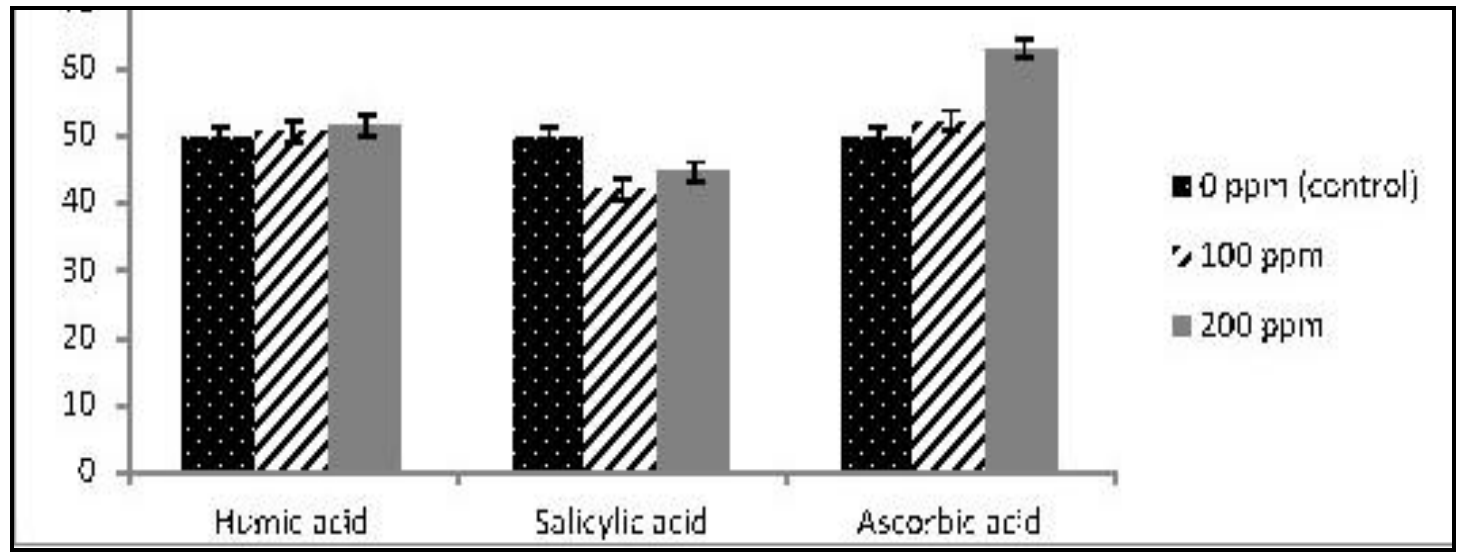

Figure 13: Means of germination stress tolerance index (GSTI) as influenced by the interaction between antioxidants types and levels.

\section{Interaction between antioxidants types and its concentrations effect}

Concerning to the interaction between antioxidant types and its concentrations effects on stress tolerance and shoot length stress indices, the results showed a significant effect of this interaction. The results clearly graphically demonstrated in Figure 13 and 14 indicated that increasing Ascorbic acid concentration to $200 \mathrm{ppm}$ significantly recorded the highest percentages of stress tolerance index (63.11) and shoot length stress index (63.98); however, the lowest percentages obtained from without antioxidant 


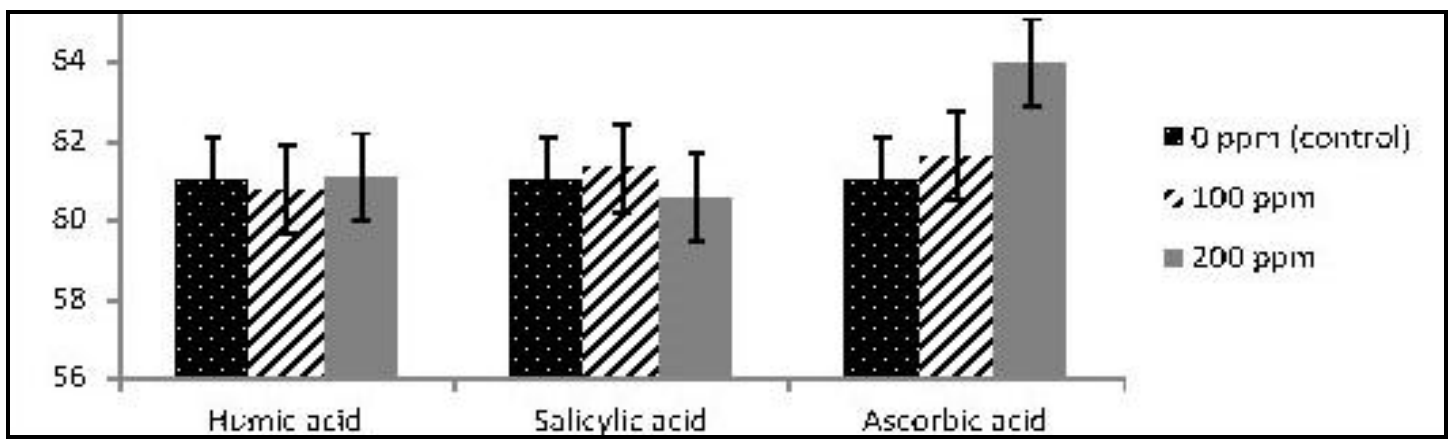

Figure 14: Means of shoot length stress index (SLSI) as influenced by the interface between antioxidants types and levels.

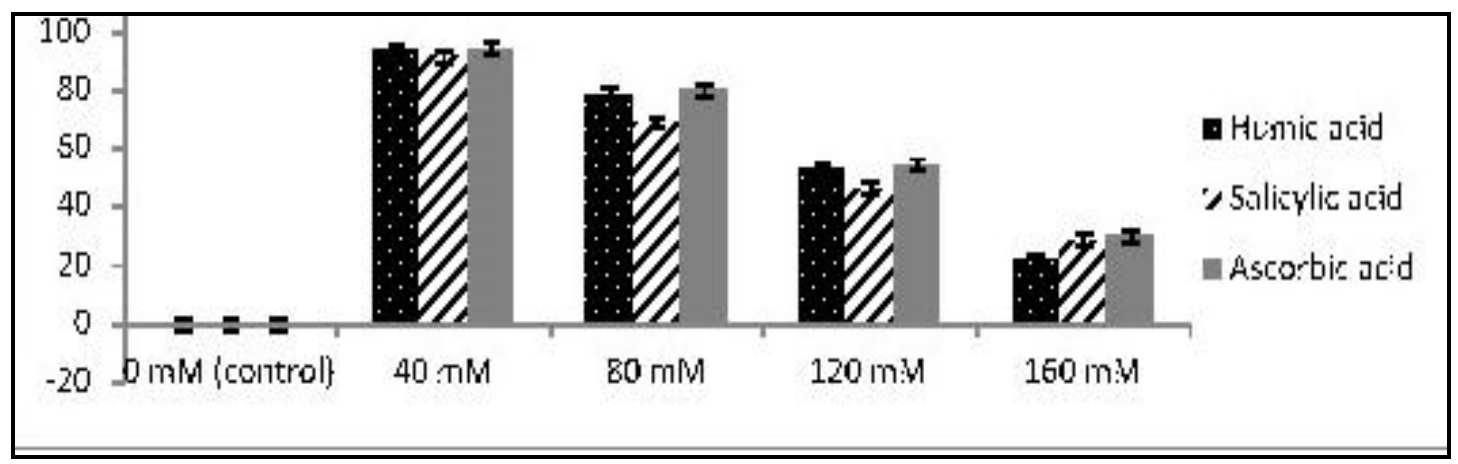

Figure 15: Averages of germination stress tolerance index (GSTI) as influenced by the interaction between antioxidants types and salinity concentrations.

types at the control treatments.

\section{Interaction between antioxidants types and salinity levels effect}

With respect to the interaction between antioxidants types and salinity level effects of germination stress tolerance index, the results indicated a significant effect of this interaction. The results clearly graphically demonstrated in Figure 15 indicated that the highest percentages of germination stress tolerance index (94.17) was obtained from soaking seed in Ascorbic acid at salinity level stress of $40 \mathrm{mM}$, however the lowest percentages (21.96) was recorded from soaking seed in Humic acid under the highest salinity level of $160 \mathrm{mM}$.

\section{Interaction among antioxidants concentrations and salinity levels effect}

With reference to the interaction between antioxidant concentration and salinity concentration effects on the germination stress tolerance, shoot length stress, shoot fresh stress and root fresh stress indices were significantly influenced by this interaction. The results clearly graphically exemplified in Figure 16, 17, 18 and 19 exposed that the highest percentages of germination stress tolerance index (93.89), shoot length stress index (95.55), shoot fresh stress index (93.14) and root fresh stress index (91.96) were recorded from increasing antioxidant levels to $200 \mathrm{ppm}$ under salinity stress of $40 \mathrm{mM}$. Nonetheless, the lowest percentages of aforementioned traits were recorded from without antioxidants soaking under the highest salinity concentration of $160 \mathrm{mM}$.

\section{Interaction between studied cultivars $\mathrm{x}$ antioxidants types $x$ antioxidants concentrations effect}

The outcomes of data presented in Tables ( 1 and 2) clearly showed that the interaction between studying wheat cultivars $\mathrm{x}$ antioxidants types $\mathrm{x}$ antioxidants concentrations insignificantly effected on the germination stress tolerance, shoot and root length stress, shoot and root fresh stress, shoot and root dry stress indices.

\section{Interaction between studied cultivars $\mathrm{x}$ antioxidants types x salinity level effect}

The outcomes of results in Tables (1 and 2) clearly showed that the interaction between studying cultivars $\mathrm{x}$ antioxidants types $\mathrm{x}$ salinity concentrations insignificantly effected on the germination stress tolerance, shoot and root length stress, shoot and root fresh stress, shoot and root 


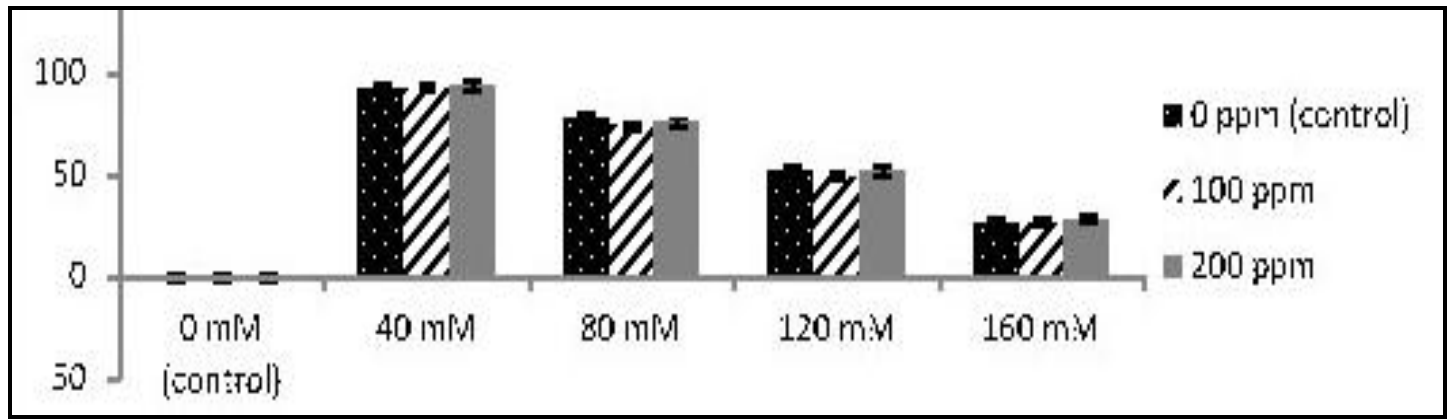

Figure 16: Means of germination stress tolerance index (GSTI) as affected by the interface between antioxidants levels and salinity levels.

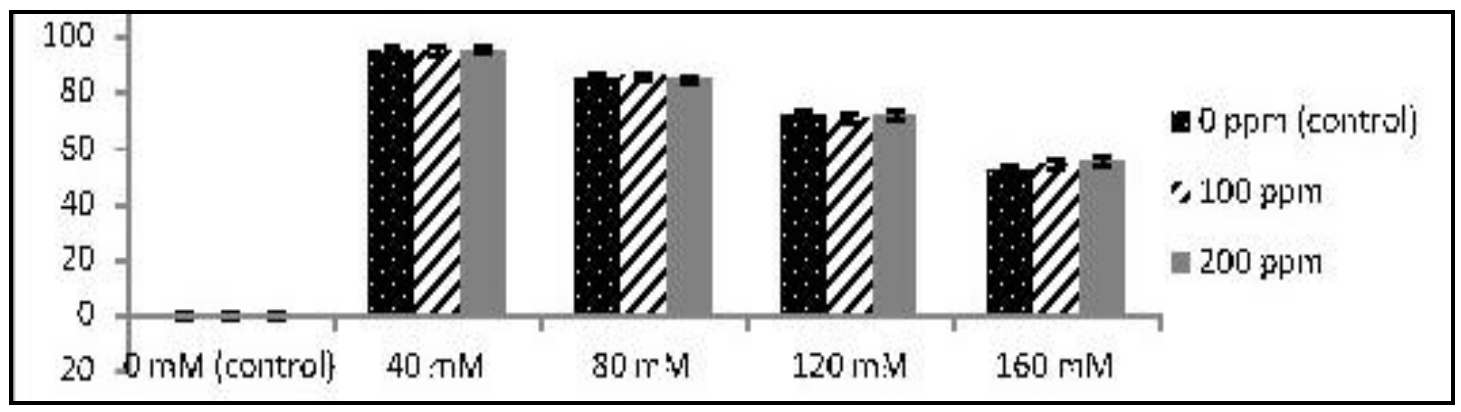

Figure 17: Means of shoot length stress index (SLSI) as affected by the interface between antioxidants levels and salinity levels.

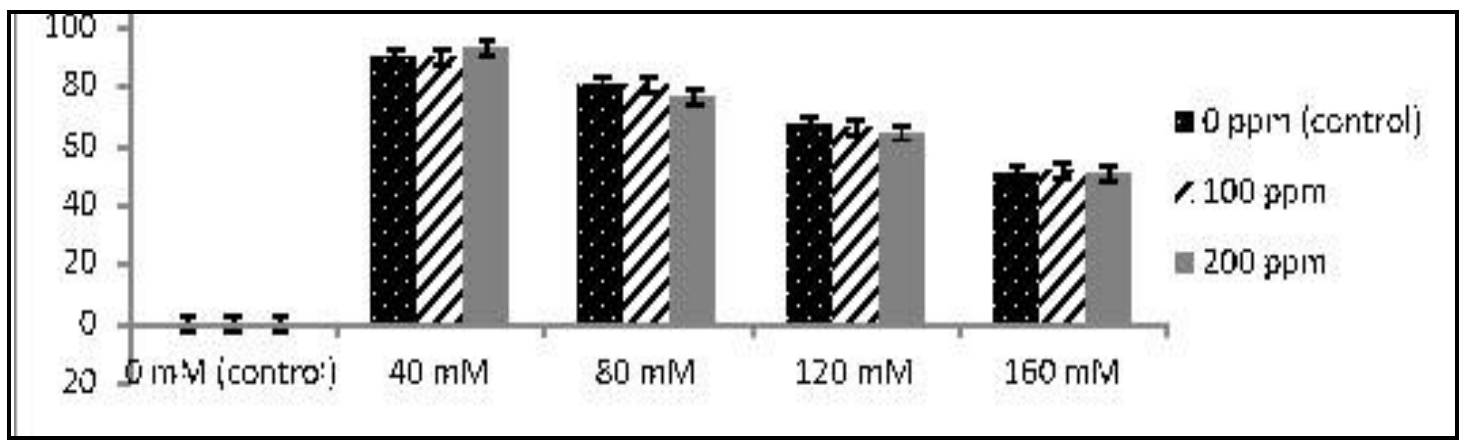

Figure 18: Means of shoot fresh stress index (SFSI) as affected by the interface between antioxidants levels and salinity levels

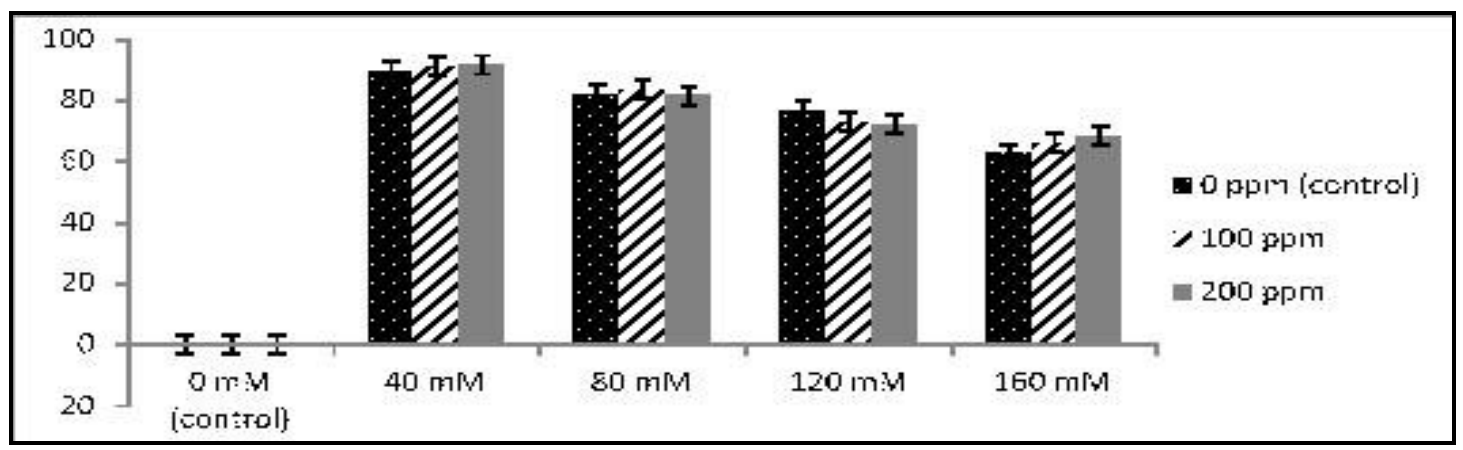

Figure 19: Averages of root fresh stress index (RFSI) as influenced by the interface between antioxidants levels and salinity levels. 
dry stress indices.

\section{Interaction between antioxidants types $x$ antioxidants concentrations $x$ salinity level effect}

Averages of germination stress tolerance index, shoot and root length stress index, shoot and root fresh stress index, shoot and root dry stress index insignificantly influenced by the interaction between antioxidants types $\mathrm{x}$ antioxidants concentrations $\mathrm{x}$ salinity levels.

\section{Interaction between studying cultivars, antioxidants types, antioxidants concentrations and salinity level effect}

The interaction among cultivars, antioxidants types, antioxidants concentrations and salinity levels insignificantly influenced means of germination stress tolerance index, shoot and root length stress index, shoot and root fresh stress index, shoot and root dry stress index.

\section{Conclusions}

Accordingly, it could recommend soaking of Gemmiza 12 or Misr 1 cultivars in concentration of $200 \mathrm{ppm}$ of ascorbic acid for $12 \mathrm{~h}$ under salinity stress for enhance physiological indices.

\section{Conflict of interests}

The authors declare that they have no conflicting interests

\section{REFERENCES}

Ahmed AAS, Uptmoor R, El-Morshidy MA, Kheiralla KA, Ali MA Mohamed NEM (2014).Some Physiological Parameters as Screening Tools for Drought Tolerance in Bread Wheat Lines (Triticum aestivum L.). World J. Agric. Res. 2(3): 109-114. CrossRef

Arzani A (2008).Improving salinity tolerance in crop plants: A biotechnological view: In-vitro Cell. Dev. Biol. Plant. 44:373-383. CrossRef

Ashraf MY, Akhter K, Hussain F, Iqbal J (2006). Screening of Different Accessions of Three Potential Grass Species from Cholistan Desert for Salt Tolerance. Pak.J.Bot.38(5): 589-1597.

Aslan D, Zencirci N, Etoz M, Ordu B, Bataw S (2015). Bread wheat responds salt stress better than einkorn wheat does during germination. Turkish J. of Agric. Forestry, 40: 783-794. CrossRef

Bafeel SO (2014). Physiological parameters of salt tolerance during germination and seedling growth of Sorghum bicolor cultivars of the same subtropical origin. Saudi J. of Biol. Scie. 21 (4): 300-304. CrossRef
Dhanda SS, Sethi GS, Behl RK (2004).Indices of drought tolerance in wheat genotypes at early stages of plant growth. J Agron. Crop Sci. 190: 6-12. CrossRef

Gomez KA, Gomez AA (1991).Statistical Procedures in Agricultural Research, John Wiley and Sons, New York. SBN: 978-0-471-87092-0.

Hamid M, Ashraf MY, Rehman KU, Arshad M (2008). Influence of salicylic acid seed priming on growth and some biochemical attributes on wheat growth under saline conditions. Pak. J. Botany, 40(1): 361-367.

ISTA Rules (2016). International seed testing association. ISTA Germination Sec. Chapter 19: pp. 19-41.

Kandil AA, Sharief AE, Elbadry DEA (2017).Seedling Parameters as affected by Soaking in Humic Acid, Salinity Stress and Grain Sorghum Genotypes. Int. J. Env. Agric. Biot. 2(6): 3213-3223.

Kausar A, Ashraf MY, Ali I, Niaz M, Abbass Q (2012). Evaluation of sorghum varieties/lines for salt tolerance using physiological indices as screening tool. Pak. J. Bot., 44(1): 47-52.

Ma L.-J, Li Y-Y, Wang L-L, Li X-M, Liu T, Bu N (2014). Germination and Physiological Response of Wheat (Triticum aestivum) to Pre-soaking with Oligochitosan. Int. J. Agric. Bio.16:766-870.

Mickky BM, Aldesuquy HS (2017). Impact of osmotic stress on seedling growth observations, membrane characteristics and antioxidant defense system of different wheat genotypes. Egyptian J. of Basic and Appl. Sci. 4: 47-54. CrossRef

Naz T, Akhtar J, Anwar-ul-Haq M, Shahid M (2015).Genetic variability in wheat genotypes for salt tolerance, growth and physiological responses. Soil Environ. 34(2): 187199.

Odjegba JV, Chukwunwike CI. (2012).Physiological responses of Amaranthus hybrids L. under salinity stress. Indian J. Innov. Deve. 1(10): 742-748.

Oyiga BC, Sharma RC, Shen J, Baum M, Ogbonnaya FC, Leon J, Ballvora A (2016). Identification and characterization of salt tolerance of wheat germplasm using a multivariable screening approach. J Agro Crop Sci. 202(6):472485. CrossRef

Ozurk A, Taşkesenligil B, Haliloğlu1 K, Aydin M, Ağlar O (2016). Evaluation of bread wheat genotypes for early drought resistance via germination under osmotic stress, cell membrane damage, and paraquat tolerance. Turkish J. of Agric. and Forestry 40: 146-159. CrossRef

Snedecor GW, Cochran WG (1980). Statistical Methods. $7^{\text {Th }}$ Ed. Iowa State University Press, Iowa, USA, Pp: 507. ISBN10: 0-81381560-6.

Yildirim M, Kizilgeci F, Akinci C, Albayrak O (2015). Response of Durum Wheat Seedlings to Salinity. Not Bot Horti Agrobo. 43(1):108-112. CrossRef

Zafar S, Yasin Ashraf M, Niaz M, Kausar A, Hussain J (2015). Evaluation of wheat genotypes for salinity tolerance using Physiological indices as screening tool. Pak. J. Bot. 47(2): 397-405. 